\title{
The Revival of Surgery in Crohn's Disease-Early Intestinal Resection as a Reasonable Alternative in Localized Ileitis
}

\author{
Matthias Kelm, Christoph-Thomas Germer, Nicolas Schlegel (D) and Sven Flemming *(D) \\ Department of General, Visceral, Transplantation, Vascular and Pediatric Surgery, Center of Operative \\ Medicine (ZOM), University Hospital of Wuerzburg, 97080 Wuerzburg, Germany; Kelm_M@ukw.de (M.K.); \\ Germer_C@ukw.de (C.-T.G.); Schlegel_N@ukw.de (N.S.) \\ * Correspondence: Flemming_S@ukw.de; Tel.: +49-931-201-0
}

Citation: Kelm, M.; Germer, C.-T.; Schlegel, N.; Flemming, S. The Revival of Surgery in Crohn's Disease-Early Intestinal Resection as a Reasonable Alternative in Localized Ileitis. Biomedicines 2021, 9, 1317. https://doi.org/10.3390/ biomedicines 9101317

Academic Editor: Giovanni Pallio

Received: 5 August 2021

Accepted: 17 September 2021

Published: 26 September 2021

Publisher's Note: MDPI stays neutral with regard to jurisdictional claims in published maps and institutional affiliations.

\begin{abstract}
Crohn's disease (CD) represents a heterogeneous and complex disease with no curative therapeutic option available to date. Current therapy is mainly antibody-based focusing on the immune system while other treatment alternatives such as surgery are considered to be "last options". However, medical therapy for CD results in mild to severe side effects in a relevant amount of patients and some patients do not respond to the medication. Following that, quality of life is often significantly reduced in this patient cohort, thus, therapeutic alternatives are urgently needed. Updated evidence has revealed that surgery such as ileocecal resection (ICR) might be a potential therapeutic option in case of localized terminal ileitis since resection at early time points improves quality of life and significantly reduces the postoperative need for immunosuppressive medication with low rates of morbidity. In addition, new surgical approaches such as Kono-S anastomosis or inclusion of the mesentery result in significantly reduced rates of disease recurrence and reoperation. Based on the new evidence, the goal of this review is to provide an update on the role of surgery as a reasonable alternative to medical therapy in the interdisciplinary treatment of patients with CD.
\end{abstract}

Keywords: surgery; Crohn's disease; terminal ileitis; inflammatory bowel disease; surgical outcome

\section{Introduction}

Crohn's disease (CD) belongs to the group of inflammatory bowel diseases and represents a major socioeconomic burden due to a rising incidence and prevalence globally making it a challenging task for all healthcare systems [1-5]. Usually, CD is diagnosed in young adulthood and occurs as a mucosal or transmural inflammation while sometimes epithelioid granulomas can be found within the gut wall. Most often CD is primarily localized in the terminal ileum (Figure 1). However, it can affect all parts of the gastrointestinal tract from the oral cavity to the anus [6]. According to the current consensus criteria, the extent of $C D$ can be defined as localized or extensive CD. Localized disease is defined as intestinal $\mathrm{CD}$ affecting $<30 \mathrm{~cm}$ in extent, which usually applies to a localization in the ileocecal region but can also be located in colonic segments or the proximal intestinal region. Extensive CD is defined as affecting $>100 \mathrm{~cm}$ in extent independent of the localization. This definition aims to recognize the inflammatory burden of the disease while it has the disadvantage of being randomly chosen and leaving an undefined "gap" in the range of $30-100 \mathrm{~cm}$ [7]. Nonetheless, the definition is important when discussing the individual therapeutic strategy for patients. Despite the relevance of CD and the increasing scientific efforts to understand this complex disease, its pathophysiology still remains unclear and no curative option exists to date [8]. This is in contrast to ulcerative colitis that is restricted to the colon and can therefore be cured surgically by resection of the whole colon. Therefore, patients with CD suffer from a life-long burden of this disease that commonly leads to a dramatic overall reduction in quality of life. Current concepts suggest that $\mathrm{CD}$ displays a multifactorial pathogenesis with genetic predisposition, aberrant immune reactions, environmental factors, altered microbiota, and changes of the gut barrier function 
all together contributing to the onset and perpetuation of the disease. Since there is no curative therapy available for $C D$, the main therapeutic goal is to induce remission in the short term and to maintain remission in the long term to restore patients' quality of life. Current therapeutic strategies mainly focus on the aberrant reaction within the immune system using anti-inflammatory and immunosuppressive medication. However, despite the introduction of new medical therapies such as biologicals during recent decades, up to $50 \%$ of patients treated with immunosuppressants did not show improvement of clinical symptoms while others suffered from mild to severe side effects resulting in reduced quality of life $[9,10]$. Common side effects include fatigue, arthralgia, recurrent infections, osteoporosis, or cancer (melanoma and lymphoma) $[9,11]$. Nevertheless, newer biologicals such as vedolizumab or ustekinumab demonstrate significantly lower rates of side effects, are considered as relatively safe treatment options in CD, and show significantly increased therapeutic efficacy [12-14]. However, rates of treatment discontinuation due to lack/loss of response even with newer biologicals remain relevant and patients with a primary nonresponse to antiTNF agents show lower rates of response to second-line biologics [11,14,15]. Following that, the development of new therapeutic strategies to not only decrease side effects but to improve patients' quality of life as well as treatment efficacy is of great interest. Accordingly, due to the lack of evidence, the option to potentially induce remission in patients by early surgical intervention has not been established in the past and surgery in $\mathrm{CD}$ was only seen as therapeutic option in case of enteric complications over a long period of time [16]. However, recent evidence challenges this view, which will most likely induce a paradigm shift in the future, while expanding the role of surgery for $\mathrm{CD}$ also raises new questions and challenges which need to be addressed. Thus, the goal of this review is to summarize the current evidence on the interdisciplinary treatment of limited CD, present new surgical strategies, and provide an outlook on future scientific and clinical issues.



Figure 1. Flow chart for treatment strategies in Crohn's disease.

\section{Historic Development of the Role of Surgery to Treat CD}

The history of $\mathrm{CD}$ and its treatment algorithm is long and includes various revolutionary milestones with its management being in consistent evolution. In 1932, Crohn, Ginzburg, and Oppenheimer were the first to report patients suffering from regional ileitis who were treated at The Mount Sinai Hospital, New York, NY, USA [17]. At that time, primary therapy of patients with regional ileitis consisted of surgical resection of the inflamed gut segments. Based on a rapid evolvement of pathophysiologic concepts, novel medical therapies have been developed resulting in the replacement of surgery as the primary treatment option for patients with CD. This development was also driven by the fear of surgical complications including the need for repeated surgery leading to short bowel 
syndrome and frequent relapses of the disease. Since then, surgical treatment has only served as an alternative approach in case of complications or refractory disease $[16,18]$. Most likely this view has led clinical researchers to define the primary focus of studies on CD medications not only on remission of the disease but also as time to avoid and delay surgery. This long-standing paradigm shift to abandon surgery as primary therapeutic option was further supported by randomized-controlled studies demonstrating that the biological-based treatment results in clinical and endoscopical improvement of patients suffering from $C D$ resulting in a decreased need of surgery during a one-year followup $[19,20]$. However, general rates of surgical resection for patients with CD outside the studies mentioned above have remained stable during the last 20 years with $20-35 \%$ during the first five years following initial diagnosis [10,21], despite the "aggressive" use of biologicals (step-down approach) [22,23]. In addition, even more powerful therapies such as biologicals initially resulted in increased rates of side effects and reduced quality of life for patients $[9,24]$. Based on this background but with newer biologicals demonstrating improved safety profiles and treatment efficacy, it is reasonable that quality of life should be chosen as primary end point for (prospective) studies on therapies for patients suffering from $C D$ in the future instead of surgery-free survival. Therefore, due to the constant rates of surgical resections in CD patients despite the introduction of new medical therapies and major scientific progress, the question about the role of surgery as therapeutic alternative, at least for subgroups of patients, needs be re-evaluated urgently.

\section{New Evidence Strengthens the Role of Early Surgical Intervention in Limited CD}

Today, consensus recommendations about surgery as therapeutic approach in patients with CD remain heterogeneous. For instance, guidelines of the American College of Gastroenterology describe surgery as reserved for severe enteric complications only such as bowel obstruction, abscess formation, perforation, or the presence of medically refractory disease (Table 1) [18].

This perspective with differences in clinical practice result in decreased numbers of CD-related surgery, which is demonstrated by data from Canada and Australia [25,26]. In contrast, the British National Institute for Health and Care Excellence (NICE) recommends surgery already at an early stage of the disease as therapeutic alternative [27]. This approach is also supported by German guidelines whereas British and German societies recommend introducing all therapeutic alternatives to patients while taking into account the state of disease as well as individual risks and benefits and personal preferences [27,28]. Similarly, updated European Crohn's and Colitis Organization (ECCO) guidelines introduce surgery as a primary treatment option in the case of localized $C D$ as an equal therapeutic alternative to Tumor Necrosis Factor alpha inhibitor infliximab. Importantly, this recommendation includes patients with active inflammation but without stenosis and represents a major adaptation in clinical practice [29]. Those adaptations in guidelines increase the relevance of surgery in CD substantially and are mainly due to new studies in the last few years. These studies demonstrated advantages for early surgical intervention especially in regard to disease recurrence and rates of reoperation. Aratari et al. showed in the postoperative histopathological reappraisal after early surgical intervention in patients with a first-time diagnosis of $\mathrm{CD}$, the disease-free interval was significantly prolonged in comparison to surgery at a later stage of the disease (median: 54.2 months) during a followup of more than 10 years $(p=0.02,95 \%$-CI $0.35-0.92)$ [30]. In the case of localized disease to the terminal ileum, data from our own patient cohort demonstrated a significantly decreased need for immunosuppressive medication postoperatively for patients who received primary ileocecal resection (ICR) compared to patients who were primarily treated medically and received surgery at a later stage $(37.9 \%$ vs. $80 \%, p=0.001)$ [31]. Importantly, rates of postoperative complications were low and no mortality was seen. The positive effect of surgery on the postoperative follow-up is underlined by studies from Italy and Hungary, which showed that early surgical intervention in patients with CD is associated with a significantly decreased need for immunosuppressive medication and rates of reoperation 
(10.8 versus 5.8 years, $p<0.01$ ) in short- and long-term follow up [32,33]. In an Australian cohort analysis, similar results were observed since early surgical intervention $(<6$ months after initial diagnosis) resulted in decreased rates of reoperation $(14.2 \%$ versus $31.3 \%$, $p=0.041)$ and less need for biologicals postoperatively (33.3\% versus $60 \%, p=0.004)$ [34] This was confirmed by the retrospective CONNECT study, which showed a significantly decreased need for biologicals after early operation during a follow up of nine years [35]. However, it must also be considered that most of these studies have a retrospective character and patient cohorts are heterogeneous due to the clinical variability of CD.

Table 1. Recommendation of international guidelines regarding isolated ileocolonic Crohn's disease.

\begin{tabular}{|c|c|}
\hline Society/Organization & Recommendation \\
\hline American College of Gastroenterology [18] & $\begin{array}{l}\text { Surgery is reserved for severe enteric } \\
\text { complications only such as bowel obstruction, } \\
\text { abscess formation, perforation or the presence of } \\
\text { medically refractory disease. }\end{array}$ \\
\hline $\begin{array}{l}\text { British National Institute for Health and Care Excellence } \\
\text { (NICE) [27] }\end{array}$ & $\begin{array}{l}\text { Surgery is recommended at an early stage of the } \\
\text { disease as therapeutic alternative to } \\
\text { medical therapy. }\end{array}$ \\
\hline $\begin{array}{l}\text { German Society of Gastroenterology (DGVS) and } \\
\text { German Society of Visceral Surgery (DGAV) [28] }\end{array}$ & $\begin{array}{l}\text { Surgery is recommended as primary treatment } \\
\text { option in case of localized CD as an equal } \\
\text { therapeutic alternative to biological } \\
\text { (medical) therapy. }\end{array}$ \\
\hline European Crohn's and Colitis Organization (ECCO) [29] & $\begin{array}{l}\text { Surgery is recommended as primary treatment } \\
\text { option in case of localized CD as an equal } \\
\text { therapeutic alternative to biological } \\
\text { (medical) therapy. }\end{array}$ \\
\hline
\end{tabular}

Nonetheless, according to those retrospective analyses there might be a potential advantage for early surgical intervention in localized CD regarding the need for antibodybased medication and reoperation. These findings are substantiated by two prospective studies comparing early surgical resection versus medical therapy. Gerdin et al. analyzed patients with isolated CD in the Swedish Crohn Trial [36]. Even though the study was terminated prematurely due to the slow inclusion rate and changes in clinical practice resulting in a small study cohort, patients who received ileocecal resection demonstrated improved quality of life and general health in comparison to patients who were randomized for medical therapy, while no differences were seen for disease activity during followup. Furthermore, in 2017, Ponsioen et al. published the LIR!C trial which compared laparoscopic ICR to infliximab therapy in patients with localized terminal ileitis [37]. In this randomized controlled trial, patients were included if localized CD was newly diagnosed and clinical course was refractory to three months of immunosuppressive medication including steroids and nonbiological drugs. After 12 months, patients showed improved quality of life following surgical resection in comparison to infliximab therapy with low morbidity rates. Furthermore, $18 \%$ of patients initially receiving medical therapy needed surgery during a follow-up of 12 months. Just recently published long-term data from the LIR!C trial re-evaluated these results. During a median follow-up of 63.5 months, $26 \%$ of patients with ICR needed antibody-based therapy postoperatively. Of those without antibody-based therapy, $48 \%$ were on immunomodulators. In comparison, $48 \%$ of patients with initial infliximab therapy had to be operated due to CD during follow-up. No patient of the infliximab-group was medication free while some of them needed therapy escalation. While the duration of treatment effect was comparable between both groups, a similar amount of patients in each group needed additional treatment during follow-up due to disease activity (approximately 60\% in each group) [38]. In addition to the LIR!C trial, Wright et al. demonstrated in a prospective trial that quality of life was significantly improved after surgical resection while the effect was sustained during a follow-up period of 18 months [39]. 


\section{Early Surgical Therapy in Crohn's Disease Is Characterized by Low Morbidity and Mortality}

Common arguments against surgery are potential surgical complications and short bowel syndrome due to the need for reoperations. However, several studies demonstrated that surgery in patients with $C D$ is a safe therapeutic approach with very low morbidity and mortality $[31,40,41]$. These observations are also based on the introduction of bowel sparing strategies such as different techniques of strictureplasty and minimal invasive surgery including endoscopic and laparoscopic approaches. In the last decade, the development of minimal invasive surgery has been dramatically accelerated due to the introduction of single-incision laparoscopic (SILS) and robotic surgery, which significantly improved the quality of surgery regarding perioperative recovery of patients, enhanced body image and cosmesis [42-44]. Furthermore, the implementation of structured perioperative patient care programs such as prehabilitation and "Fast Track Surgery" / "ERAS" (enhanced recovery after surgery) results in earlier recovery and decreased morbidity [45-47]. These perioperative and surgical developments and advancements help to partially offset the negative impact of patient's comorbidities and complicated disease phenotype on postoperative outcomes including disease-, surgical- and nonsurgical-related complications.

In general, even if laparoscopic surgery shows similar results regarding disease recurrence, the laparoscopic approach should be preferred since the advantages of minimallyinvasive surgical techniques are well established as mentioned above [40,48]. However, due to its complexity, Crohn's surgery should be performed in high-volume centers only since an interdisciplinary treatment approach is necessary and rates of complications are associated with the center's and surgeon's experience $[49,50]$. This is in part due to increased rates of laparoscopic approaches and improved complication management but also due to regular interdisciplinary interactions between gastroenterologists and surgeons which provides optimal evidence-based and individualized patient care. Adequate planning and risk management of CD-related surgery based on the center's experience is critical to reduce surgical complications and in-hospital mortality as well as to increase the patient's quality of life [51,52]. Short bowel syndrome is a complication which needs to be avoided urgently and strategies for bowel preserving surgery such as resecting as little bowel as necessary as well as strictureplasty are well established [29,53]. A further advantage of early surgical intervention is that usually less bowel segments need to be resected, thus, bowel preserving surgery can be performed more easily at early time points of $\mathrm{CD}$. This is especially relevant since rates for reoperation are decreased and disease-free survival prolonged after early surgery as outlined before. In case of surgical intervention at a later time point, extended resections are often necessary since there is an increased risk for complications such as conglomerates, fistulas, or abscesses making the principle of bowel preserving surgery difficult if not even impossible [54].

\section{Early Surgical Therapy Seems to Be Associated with Decreased Health Care Costs}

It is well known that Crohn's disease as a life-long disease causes relevant healthcare costs which are mainly driven by biological therapy [5,55-59]. Furthermore, the introduction of biological-based treatments were associated with increased rates of (severe) side effects resulting in additional health-care costs [60]. Therefore, besides patients outcome parameters, health-related cost-effectiveness plays an important role in health care systems worldwide as well. Based on the study population of the LIR!C trial, De Groof et al. demonstrated that mean total direct health care-related costs per patient at one year were significantly lower in the group of patients with surgical resection compared to patients receiving infliximab (mean difference -8931€) [38]. Similarly, the POCER study confirmed that postoperative $\mathrm{CD}$ associated costs are primarily medication-related [61]. Therefore, while further studies are needed to compare the cost-effectiveness of other medications than infliximab as well as biosimilars to draw a final conclusion, the initial results demonstrate a potential benefit for surgical resection regarding cost-effectiveness in $\mathrm{CD}$ therapy at least in comparison to original biologicals. 


\section{Improved Surgical Technique May Further Support the Beneficial Effects of Surgery to Maintain Remission in CD}

Aside from the progress in medical therapy, there has been also a development in surgical techniques for Crohn's disease resulting in significant improvements for patient outcome [40,62]. While laparoscopic surgery was introduced in the twentieth century, its advancement has resulted in significantly decreased hospitalization rates, complications, and overall morbidity while showing a similar effect on disease outcome compared to open surgery. In general, side-to-side anastomoses are associated with lower rates of postoperative recurrence than end-to-end anastomoses and should therefore be preferred [29,63]. Within the last decade, a new technique for anastomosis in CD was introduced by Kono et al. [64]. This technique (Kono-S anastomosis) is based on the idea that the inflammation in CD originates from the mesentery so the anastomosis should be created as far away as possible from it (antimesenteric handsewn anastomosis) while avoiding devascularization and denervation of the tissue. In addition, other key factors such as a large lumen to avoid fecal stasis and provide functional peristalsis as well as healthy intestinal segments were also included in the concept of Kono et al. Initial studies demonstrate impressive results regarding the risk of surgical recurrence in $\mathrm{CD}$ with a surgical recurrence-free survival of more than $95 \%$ after 10 years following Kono-S anastomosis [41]. Importantly, while endoscopic recurrence rates were comparable between both groups, additive postoperative application of infliximab significantly decreased the number of surgical recurrences in patients with conventional anastomoses [64]. In addition, a recent meta-analysis revealed a strongly decreased mean Rutgeert score and an endoscopic recurrence of only $5 \%$ while rates of overall complications were rare [65]. The first randomized-controlled trial (SuPREMe-CD study) compared Kono-S anastomosis versus a conventional latero-lateral anastomosis and confirmed the significant reduction in postoperative endoscopic and clinical recurrence after a followup of 24 months [66]. Further, international multicenter trials are currently recruiting patients and preliminary results are expected during the upcoming years (NCT03256240).

Moreover, there has been a growing body of evidence that $\mathrm{CD}$ might be a primary mesenteropathy in recent years [67-71]. In line with the principle of CD originating from the mesentery, Coffey et al. demonstrated that the inclusion of the mesentery during ICR results in significantly reduced rates of reoperation compared to conventional ICR ( $40 \%$ versus $2.9 \%, p=0.007$ ) [72]. However, while the two patient cohorts included in this study were small ( 30 versus 34 patients), patients without resection of the mesentery had increased rates of positive resection margins ( $79 \%$ versus $16 \%$ ), which might be associated with increased rates of recurrence. Therefore, due to the heterogeneity of both cohorts in this study the conclusion about the role of the mesentery remains open and needs to be further evaluated. To answer the question of whether mesocolic excision during primary ICR reduces postoperative disease recurrence, an international multicenter randomized trial is currently in process [73].

When discussing the role of surgery in inflammatory diseases, Crohn's disease in particular, positive resection margins and their potential consequences regarding disease recurrence are a highly relevant field but a standardized algorithm is missing. While the evidence regarding resection margins is clearly defined in case of oncological diseases, the consequence of positive resection margins in case of terminal ileitis remains open. Regarding anastomotic leakage, Garofalo et al. reported that a positive proximal resection margin is associated with increased rates of anastomotic leakage postoperatively in comparison to patients without microscopic involvement of inflammatory cells of the anastomosis [74]. However, Schineis et al. and Aaltonen et al. reported in single center studies that no differences regarding anastomotic leakages were seen following microscopic inflammation, and that overall postoperative complications rates were low $[75,76]$. Similarly, analyzing our own cohort we did not see increased rates of anastomotic leakages for patients with positive resection margins following ileocecal resection (data not published yet). Therefore, 
due to the heterogeneous evidence, extended resections are currently not recommended but further data are needed to analyze the question in more detail.

A different question, however, is the role of positive resection margins on postoperative disease recurrence. This is especially relevant in cases of early endoscopic and/or clinical recurrence. While the exact pathogenesis for postoperative recurrence is unknown, various risk factors such as smoking, granulomas in the resection specimen, previous intestinal resection, and myenteric plexitis have been identified [77-79]. However, the relationship between positive resection margins and early disease recurrence remains unknown and a standard algorithm is missing. Different studies demonstrated a significantly increased risk for endoscopic recurrence following ileocecal resection in case of microscopic inflammation at the resection margins. Following ileocecal resection, Poredska et al. showed that $56.5 \%$ of patients with positive resection margins suffered from endoscopic recurrence after six months in comparison to $4.8 \%$ with noninflamed resection margins $(p<0.001)$ [80]. Furthermore, another study from France confirmed an increased risk of clinical and surgical recurrence after resection in case of a positive histological margin. During a follow up of five years, $51 \%$ of patients with positive margins had disease recurrence while $34 \%$ had not $(p=0.034)$. [81] This is underlined by a multicenter study which demonstrated that a transmural lesion, especially at the oral resection margin, is independently associated with an increased risk for postoperative recurrence ( $75 \%$ versus $46 \%$ ) [82]. Interestingly, Wasman et al. demonstrated in more detail that patients with active inflammation at the colonic resection margin after ICR might have a different and more aggressive disease and might require more intense medical treatment [83]. Furthermore, two recent meta-analyses demonstrated that histological positive resection margins increased clinical and surgical recurrence with a trend towards endoscopic recurrence but definitions of margin positivity and postoperative recurrence varied throughout the studies and limited the final conclusion $[78,79]$. Despite the presented studies above, the overall evidence remains heterogeneous with various studies showing no effect for resection margins on the postoperative course of disease. For instance, Zemel et al. did not find differences for clinical or endoscopic recurrence on patients with CD following ICR in a retrospective study. While the mean time from surgery to recurrence was comparable between both groups ( 4.5 versus 4.4 years), $75.5 \%$ of patients with a positive resection margin suffered from recurrence compared to $69.9 \%$ without microscopic inflammation $(p=0.57)$ [84]. Furthermore, in a single center study from Finland no significant differences were seen regarding the postoperative rates of disease recurrence in case of active inflammation at the resection margin [76]. Since the goal of CD surgery is usually a limited bowel resection to avoid short-bowl syndrome, extended resections are not supported based on the available evidence to date. On the other hand, the role of resection margins in Crohn's disease remains a double-edged sword because the removal of microscopic inflammation might decrease disease recurrence and the postoperative need for anti-inflammatory or immunosuppressive medication. Therefore, further prospective randomized studies are necessary to clearly determine the role of resections margins in regard of anastomotic leakage and disease recurrence for patients with $\mathrm{CD}$ following ileocecal resection.

\section{Summary and Future Perspectives}

Overall, despite the introduction of new medical therapies such as biologicals, the treatment of $C D$ and its complications remains challenging. While initial studies revealed promising results for new types of medical therapy, these highly promising outcomes could not be confirmed by data outside of these studies. Rates of severe side effects were especially high for older biologicals but newer biologicals such as vedolizumab or ustekinumab have been shown to be relatively safe and effective treatment options [9,11-14]. However, rates of treatment discontinuation remain relevant even with newer biologicals due to lack/loss of response $[14,15]$. Furthermore, the primary endpoint of studies should not be operationfree survival, but quality of life and remission as revealed by clinical and endoscopy scores. An additional (secondary) aspect may be cost-effectiveness but evaluation for the cost 
reduction by biosimilars is still lacking. For the parameters of quality of life and cost effectiveness, recent data revealed advantages for early surgical intervention in a subgroup of patients with localized ileocecal CD while demonstrating low rates of postoperative complications $[31,37,38,85]$. Thus, ICR is a safe therapeutic alternative to medical therapy in this special cohort.

Based on the current evidence, all available therapeutic alternatives (medical versus surgical) should be discussed with patients with localized ileocecal CD early, considering the risks and benefits as well as the personal preferences of patients as already recommended by British (NICE) and European (ECCO) guidelines [27,29]. This is an important and relevant development since surgery was indicated only in case of therapeutic refraction or enteric complications in the past. However, optimal treatment regimens remain controversial and not only medical but also surgical improvements are necessary to improve long-term outcome for patients with $\mathrm{CD}$. A major difficulty for the adequate interpretation and comparison of studies about therapies in patients with $C D$ remains the heterogeneity of patient cohorts as well as the complexity of the disease with multiple confounders. Aside from larger, homogenous prospective studies, new scientific approaches should also be included to optimize the effect of medical therapy and to reduce side effects by thinking outside the box and not only inhibit inflammation by immunosuppressants or antibody-mediated medications but also support mucosal and histological healing with new classes of drugs. In addition, operative strategies and surgical techniques such as the Kono-S anastomosis and minimally-invasive/robotic-assisted surgery needs to be developed further as well. This includes important aspects such as the role of positive resection margins and resection of the mesentery, which will be part of future analysis and might provide the potential to decrease postoperative recurrence rates. Thus, medical and surgical approaches to improve multidisciplinary treatment regimens mainly focusing on the individual patient's quality of life are essential. Importantly, strategies not only for primary treatment but also for remission prophylaxis need to be evaluated and optimized as well. Due to the complexity and heterogeneity of $C D$, individual therapeutic regimens should be in the center of future patient-directed therapies (Figure 1). Thus, all disease- and treatment-related side effects including medical and surgical side effects need to be considered to provide optimal and individualized care for patients suffering from $\mathrm{CD}$ which can be only achieved by an interdisciplinary team of gastroenterologists, radiologists, pathologists, and surgeons with regular and open-minded communication.

\section{Conclusions}

There has been a renaissance of surgical approaches in the multidisciplinary treatment of isolated Crohn's disease with improved quality of life and fewer side effects based on new evidence in recent years. Nevertheless, further efforts are still needed to develop and introduce novel medical and surgical therapy options to continuously improve the outcome of patients suffering from Crohn's disease. To do so, sufficient cooperation between medical and surgical therapeutic approaches is critical.

Author Contributions: Conceptualization, S.F. and M.K.; resources, C.-T.G.; data curation, M.K.; writing-original draft preparation, M.K. and S.F.; writing—review and editing, N.S. and C.-T.G.; supervision, S.F. and N.S. All authors have read and agreed to the published version of the manuscript.

Funding: This research received no external funding.

Institutional Review Board Statement: Not applicable.

Informed Consent Statement: Not applicable.

Conflicts of Interest: The authors declare no conflict of interest. 


\section{References}

1. Fullerton, J.N.; Gilroy, D.W. Resolution of inflammation: A new therapeutic frontier. Nat. Rev. Drug Discov. 2016, 15, 551-567. [CrossRef]

2. Ng, S.C.; Shi, H.Y.; Hamidi, N.; Underwood, F.E.; Tang, W.; Benchimol, E.I.; Panaccione, R.; Ghosh, S.; Wu, J.C.Y.; Chan, F.K.L.; et al Worldwide incidence and prevalence of inflammatory bowel disease in the 21st century: A systematic review of population-based studies. Lancet 2017, 390, 2769-2778. [CrossRef]

3. Alatab, S.; Sepanlou, S.G.; Ikuta, K.; Vahedi, H.; Bisignano, C.; Safiri, S.; Sadeghi, A.; Nixon, M.R.; Abdoli, A.; Abolhassani, H.; et al. The global, regional, and national burden of inflammatory bowel disease in 195 countries and territories, 1990-2017: A systematic analysis for the Global Burden of Disease Study 2017. Lancet Gastroenterol. Hepatol. 2020, 5, 17-30. [CrossRef]

4. Kaplan, G.G.; Windsor, J.W. The four epidemiological stages in the global evolution of inflammatory bowel disease. Nat. Rev. Gastroenterol. Hepatol. 2021, 18, 56-66. [CrossRef]

5. Zhao, M.; Gönczi, L.; Lakatos, P.L.; Burisch, J. The Burden of Inflammatory Bowel Disease in Europe in 2020. J. Crohn's Colitis 2021. [CrossRef]

6. Baumgart, D.C.; Sandborn, W.J. Crohn's disease. Lancet 2012, 380, 1590-1605. [CrossRef]

7. Gomollón, F.; Dignass, A.; Annese, V.; Tilg, H.; Van Assche, G.; Lindsay, J.O.; Peyrin-Biroulet, L.; Cullen, G.J.; Daperno, M.; Kucharzik, T.; et al. 3rd European Evidence-based Consensus on the Diagnosis and Management of Crohn's Disease 2016: Part 1: Diagnosis and Medical Management. J. Crohns Colitis 2017, 11, 3-25. [CrossRef]

8. Chang, J.T. Pathophysiology of Inflammatory Bowel Diseases. N. Engl. J. Med. 2020, 383, 2652-2664. [CrossRef] [PubMed]

9. Cushing, K.; Higgins, P.D.R. Management of Crohn Disease: A Review. JAMA 2021, 325, 69-80. [CrossRef]

10. Burisch, J.; Kiudelis, G.; Kupcinskas, L.; Kievit, H.A.L.; Andersen, K.W.; Andersen, V.; Salupere, R.; Pedersen, N.; Kjeldsen, J.; D'Incà, R.; et al. Natural disease course of Crohn's disease during the first 5 years after diagnosis in a European population-based inception cohort: An Epi-IBD study. Gut 2019, 68, 423. [CrossRef]

11. Biemans, V.B.C.; van der Meulen, A.E.; van der Woude, C.J.; Löwenberg, M.; Dijkstra, G.; Oldenburg, B.; De Boer, N.K.; Van Der Marel, S.; Bodelier, A.G.; Jansen, J.M.; et al. Ustekinumab for Cohn's Disease: Results of the ICC Registry, a Nationwide Prospective Observational Cohort Study. J. Crohns Colitis 2020, 14, 33-45. [CrossRef]

12. Ma, C.; Fedorak, R.N.; Kaplan, G.G.; Dieleman, L.A.; Devlin, S.M.; Stern, N.; Kroeker, K.I.; Seow, C.H.; Leung, Y.; Novak, K.L.; et al. Long-term Maintenance of Clinical, Endoscopic, and Radiographic Response to Ustekinumab in Moderate-to-Severe Crohn's Disease: Real-world Experience from a Multicenter Cohort Study. Inflamm. Bowel Dis. 2017, 23, 833-839. [CrossRef] [PubMed]

13. Sandborn, W.J.; Feagan, B.G.; Rutgeerts, P.; Hanauer, S.; Colombel, J.F.; Sands, B.E.; Lukas, M.; Fedorak, R.N.; Lee, S.; Bressler, B.; et al. Vedolizumab as induction and maintenance therapy for Crohn's disease. N. Engl. J. Med. 2013, 369, 711721. [CrossRef]

14. Vermeire, S.; Loftus, E.V., Jr.; Colombel, J.F.; Feagan, B.G.; Sandborn, W.J.; Sands, B.E.; Danese, S.; D’Haens, G.R.; Kaser, A.; Panaccione, R.; et al. Long-term Efficacy of Vedolizumab for Crohn's Disease. J. Crohns Colitis 2017, 11, 412-424. [CrossRef] [PubMed]

15. Singh, S.; George, J.; Boland, B.S.; Casteele, N.V.; Sandborn, W.J. Primary Non-Response to Tumor Necrosis Factor Antagonists is Associated with Inferior Response to Second-line Biologics in Patients with Inflammatory Bowel Diseases: A Systematic Review and Meta-analysis. J. Crohns Colitis 2018, 12, 635-643. [CrossRef] [PubMed]

16. Gionchetti, P.; Dignass, A.; Danese, S.; Magro Dias, F.J.; Rogler, G.; Lakatos, P.L.; Adamina, M.; Ardizzone, S. '; Buskens, C.J.; Sebastian, S.; et al. 3rd European Evidence-based Consensus on the Diagnosis and Management of Crohn's Disease 2016: Part 2: Surgical Management and Special Situations. J. Crohns Colitis 2017, 11, 135-149. [CrossRef] [PubMed]

17. Crohn, B.B.; Ginzburg, L.; Oppenheimer, G.D. Landmark article Oct 15, 1932. Regional ileitis. A pathological and clinical entity. By Burril, B. Crohn, Leon Ginzburg, and Gordon, D. Oppenheimer. JAMA 1984, 251, 73-79. [CrossRef] [PubMed]

18. Lichtenstein, G.R.; Loftus, E.V.; Isaacs, K.L.; Regueiro, M.D.; Gerson, L.B.; Sands, B.E. ACG Clinical Guideline: Management of Crohn's Disease in Adults. Am. J. Gastroenterol. 2018, 113, 481-517. [CrossRef] [PubMed]

19. Rutgeerts, P.; Feagan, B.G.; Lichtenstein, G.R.; Mayer, L.F.; Schreiber, S.; Colombel, J.F.; Rachmilewitz, D.; Wolf, D.C.; Olson, A.; Bao, W.; et al. Comparison of scheduled and episodic treatment strategies of infliximab in Crohn's disease. Gastroenterology 2004, 126, 402-413. [CrossRef]

20. Feagan, B.G.; Panaccione, R.; Sandborn, W.J.; D’Haens, G.R.; Schreiber, S.; Rutgeerts, P.J.; Loftus Jr, E.V.; Lomax, K.G.; Yu, A.P.; Wu, E.Q.; et al. Effects of adalimumab therapy on incidence of hospitalization and surgery in Crohn's disease: Results from the CHARM study. Gastroenterology 2008, 135, 1493-1499. [CrossRef]

21. Wong, D.J.; Roth, E.M.; Feuerstein, J.D.; Poylin, V.Y. Surgery in the age of biologics. Gastroenterol. Rep. 2019, 7, 77-90. [CrossRef]

22. Antunes, O.; Filippi, J.; Hébuterne, X.; Peyrin-Biroulet, L. Treatment algorithms in Crohn's—Up, down or something else? Best Pract. Res. Clin. Gastroenterol. 2014, 28, 473-483. [CrossRef]

23. Berg, D.R.; Colombel, J.F.; Ungaro, R. The Role of Early Biologic Therapy in Inflammatory Bowel Disease. Inflamm. Bowel Dis. 2019, 25, 1896-1905. [CrossRef]

24. Voskuil, M.D.; Bangma, A.; Weersma, R.K.; Festen, E.A.M. Predicting (side) effects for patients with inflammatory bowel disease: The promise of pharmacogenetics. World J. Gastroenterol. 2019, 25, 2539-2548. [CrossRef] 
25. Toh, J.W.T.; Wang, N.; Young, C.J.; Rickard, M.; Keshava, A.; Stewart, P.; Kariyawasam, V.; Leong, R. Major Abdominal and Perianal Surgery in Crohn's Disease: Long-term Follow-up of Australian Patients With Crohn's Disease. Dis. Colon Rectum 2018, 61, 67-76. [CrossRef] [PubMed]

26. Dittrich, A.E.; Sutton, R.T.; Haynes, K.; Wang, H.; Fedorak, R.N.; Kroeker, K.I. Incidence Rates for Surgery in Crohn's Disease Have Decreased: A Population-based Time-trend Analysis. Inflamm. Bowel Dis. 2020, 26, 1909-1916. [CrossRef] [PubMed]

27. Martins, R.; Carmona, C.; George, B.; Epstein, J. Management of Crohn's disease: Summary of updated NICE guidance. BMJ 2019, 367, 15940. [CrossRef]

28. Preiß, J.C.; Bokemeyer, B.; Buhr, H.J.; Dignaß, A.; Häuser, W.; Hartmann, F.; Herrlinger, K.R.; Kaltz, B.; Kienle, P.; Kruis, W.; et al. Updated German clinical practice guideline on "Diagnosis and treatment of Crohn's disease" 2014. Z. Gastroenterol. 2014, 52, 1431-1484.

29. Adamina, M.; Bonovas, S.; Raine, T.; Spinelli, A.; Warusavitarne, J.; Armuzzi, A.; Bachmann, O.; Bager, P.; Biancone, L.; Bokemeyer, B.; et al. ECCO Guidelines on Therapeutics in Crohn's Disease: Surgical Treatment. J. Crohns Colitis 2020, 14, 155-168. [CrossRef] [PubMed]

30. Aratari, A.; Papi, C.; Leandro, G.; Viscido, A.; Capurso, L.; Caprilli, R. Early versus late surgery for ileo-caecal Crohn's disease. Aliment. Pharmacol. Ther. 2007, 26, 1303-1312. [CrossRef] [PubMed]

31. Kelm, M.; Anger, F.; Eichlinger, R.; Brand, M.; Kim, M.; Reibetanz, J.; Krajinovic, K.; Germer, C.T.; Schlegel, N.; Flemming, S. Early Ileocecal Resection Is an Effective Therapy in Isolated Crohn's Disease. J. Clin. Med. 2021, 10, 731. [CrossRef]

32. Golovics, P.A.; Lakatos, L.; Nagy, A.; Pandur, T.; Szita, I.; Balogh, M.; Molnar, C.; Komaromi, E.; Lovasz, B.D.; Mandel, M.; et al. Is early limited surgery associated with a more benign disease course in Crohn's disease? World J. Gastroenterol. 2013, 19, 7701-7710. [CrossRef]

33. Latella, G.; Cocco, A.; Angelucci, E.; Viscido, A.; Bacci, S.; Necozione, S.; Caprilli, R. Clinical course of Crohn's disease first diagnosed at surgery for acute abdomen. Dig. Liver Dis. 2009, 41, 269-276. [CrossRef]

34. An, V.; Cohen, L.; Lawrence, M.; Thomas, M.; Andrews, J.; Moore, J. Early surgery in Crohn's disease a benefit in selected cases. World J. Gastrointest. Surg. 2016, 8, 492-500. [CrossRef] [PubMed]

35. Lee, J.M.; Lee, K.M.; Kim, J.S.; Kim, Y.S.; Cheon, J.H.; Ye, B.D.; Kim, Y.H.; Han, D.S.; Lee, C.K. Park HJ. Postoperative course of Crohn disease according to timing of bowel resection: Results from the CONNECT Study. Medicine 2018, 97, e0459. [CrossRef] [PubMed]

36. Gerdin, L.; Eriksson, A.S.; Olaison, G.; Sjödahl, R.; Ström, M.; Söderholm, J.D.; Myrelid, P. The Swedish Crohn Trial: A Prematurely Terminated Randomized Controlled Trial of Thiopurines or Open Surgery for Primary Treatment of Ileocaecal Crohn's Disease. J. Crohns Colitis 2016, 10, 50-54. [CrossRef] [PubMed]

37. Ponsioen, C.Y.; de Groof, E.J.; Eshuis, E.J.; Gardenbroek, T.J.; Bossuyt, P.M.M.; Hart, A.; Warusavitarne, J.; Buskens, C.J.; van Bodegraven, A.A.; Brink, M.A.; et al. Laparoscopic ileocaecal resection versus infliximab for terminal ileitis in Crohn's disease: A randomised controlled, open-label, multicentre trial. Lancet Gastroenterol. Hepatol. 2017, 2, 785-792. [CrossRef]

38. De Groof, E.J.; Stevens, T.W.; Eshuis, E.J.; Gardenbroek, T.J.; Bosmans, J.E.; van Dongen, J.M.; Mol, B.; Buskens, C.J.; Stokkers, P.C.F.; Hart, A.; et al. Cost-effectiveness of laparoscopic ileocaecal resection versus infliximab treatment of terminal ileitis in Crohn's disease: The LIR!C Trial. Gut 2019, 68, 1774-1780. [CrossRef]

39. Wright, E.K.; Kamm, M.A.; De Cruz, P.; Hamilton, A.L.; Ritchie, K.J.; Krejany, E.O.; Gorelik, A.; Liew, D.; Prideaux, L.; Lawrance, I.C.; et al. Effect of intestinal resection on quality of life in Crohn's disease. J. Crohns Colitis 2015, 9, 452-462. [CrossRef]

40. Patel, S.V.; Patel, S.V.; Ramagopalan, S.V.; Ott, M.C. Laparoscopic surgery for Crohn's disease: A meta-analysis of perioperative complications and long term outcomes compared with open surgery. BMC Surg. 2013, 13, 14. [CrossRef]

41. Kono, T.; Fichera, A.; Maeda, K.; Sakai, Y.; Ohge, H.; Krane, M.; Katsuno, H.; Fujiya, M. Kono-S Anastomosis for Surgical Prophylaxis of Anastomotic Recurrence in Crohn's Disease: An International Multicenter Study. J. Gastrointest. Surg. 2016, 20, 783-790. [CrossRef] [PubMed]

42. Eshuis, E.J.; Slors, J.F.; Stokkers, P.C.; Sprangers, M.A.; Ubbink, D.T.; Cuesta, M.A.; Pierik, E.G.; Bemelman, W.A. Long-term outcomes following laparoscopically assisted versus open ileocolic resection for Crohn's disease. Br. J. Surg. 2010, 97, 563-568. [CrossRef] [PubMed]

43. Rijcken, E.; Mennigen, R.; Argyris, I.; Senninger, N.; Bruewer, M. Single-incision laparoscopic surgery for ileocolic resection in Crohn's disease. Dis. Colon. Rectum. 2012, 55, 140-146. [CrossRef] [PubMed]

44. Raskin, E.R.; Gorrepati, M.L.; Mehendale, S.; Gaertner, W.B. Robotic-assisted ileocolic resection for Crohn's disease: Outcomes from an early national experience. J. Robot. Surg. 2019, 13, 429-434. [CrossRef]

45. Fiorindi, C.; Cuffaro, F.; Piemonte, G.; Cricchio, M.; Addasi, R.; Dragoni, G.; Scaringi, S.; Nannoni, A.; Ficari, F.; Giudici, F. Effect of long-lasting nutritional prehabilitation on postoperative outcome in elective surgery for IBD. Clin. Nutr. 2021, 40, 928-935. [CrossRef]

46. Patel, K.V.; Darakhshan, A.A.; Griffin, N.; Williams, A.B.; Sanderson, J.D.; Irving, P.M. Patient optimization for surgery relating to Crohn's disease. Nat. Rev. Gastroenterol. Hepatol. 2016, 13, 707-719. [CrossRef]

47. Fiorino, G.; Allocca, M.; Chaparro, M.; Coenen, S.; Fidalgo, C.; Younge, L.; Gisbert, J.P. 'Quality of Care' Standards in Inflammatory Bowel Disease: A Systematic Review. J. Crohn's Colitis 2018, 13, 127-137. [CrossRef]

48. Dasari, B.V.; McKay, D.; Gardiner, K. Laparoscopic versus Open surgery for small bowel Crohn's disease. Cochrane Database Syst. Rev. 2011, CD006956. [CrossRef] 
49. Kaplan, G.G.; McCarthy, E.P.; Ayanian, J.Z.; Korzenik, J.; Hodin, R.; Sands, B.E. Impact of Hospital Volume on Postoperative Morbidity and Mortality Following a Colectomy for Ulcerative Colitis. Gastroenterology 2008, 134, 680-687.e1. [CrossRef]

50. Nguyen, G.C.; Steinhart, A.H. The Impact of Surgeon Volume on Postoperative Outcomes After Surgery for Crohn's Disease. Inflamm. Bowel Dis. 2013, 20, 301-306. [CrossRef]

51. Reindl, W.; Thomann, A.K.; Galata, C.; Kienle, P. Reducing Perioperative Risks of Surgery in Crohn's Disease. Visc Med. 2019, 35, 348-354. [CrossRef]

52. Ananthakrishnan, A.N.; McGinley, E.L.; Binion, D.G. Does it matter where you are hospitalized for inflammatory bowel disease? A nationwide analysis of hospital volume. Am. J. Gastroenterol. 2008, 103, 2789-2798. [CrossRef]

53. Meima-van Praag, E.M.; Buskens, C.J.; Hompes, R.; Bemelman, W.A. Surgical management of Crohn's disease: A state of the art review. Int. J. Colorectal Dis. 2021, 36, 1133-1145. [CrossRef] [PubMed]

54. Iesalnieks, I.; Kilger, A.; Glaß, H.; Obermeier, F.; Agha, A.; Schlitt, H.J. Perforating Crohn's ileitis: Delay of surgery is associated with inferior postoperative outcome. Inflamm. Bowel Dis. 2010, 16, 2125-2130. [CrossRef]

55. Kuenzig, M.E.; Benchimol, E.I.; Lee, L.; Targownik, L.E.; Singh, H.; Kaplan, G.G.; Bernstein, C.N.; Bitton, A.; Nguyen, G.C.; Lee, K.; et al. The Impact of Inflammatory Bowel Disease in Canada 2018: Direct Costs and Health Services Utilization. J. Can. Assoc. Gastroenterol. 2019, 2 (Suppl. 1), S17-S33. [CrossRef] [PubMed]

56. Burisch, J.; Vardi, H.; Pedersen, N.; Brinar, M.; Cukovic-Cavka, S.; Kaimakliotis, I.; Duricova, D.; Bortlik, M.; Shonová, O.; Vind, I.; et al. Costs and resource utilization for diagnosis and treatment during the initial year in a European inflammatory bowel disease inception cohort: An ECCO-EpiCom Study. Inflamm. Bowel Dis. 2015, 21, 121-131. [CrossRef] [PubMed]

57. Park, K.T.; Ehrlich, O.G.; Allen, J.I.; Meadows, P.; Szigethy, E.M.; Henrichsen, K.; Kim, S.C.; Lawton, R.C.; Murphy, S.M.; Regueiro, M.; et al. The Cost of Inflammatory Bowel Disease: An Initiative From the Crohn's \& Colitis Foundation. Inflamm. Bowel Dis. 2020, 26, 1-10. [PubMed]

58. Brandes, A.; Growth, A.; Gottschalk, F.; Wilke, T.; Ratsch, B.A.; Orzechowski, H.D.; Fuchs, A.; Deiters, B.; Bokemeyer, B. Real-world biologic treatment and associated cost in patients with inflammatory bowel disease. Z. Gastroenterol. 2019, 57, 843-851. [CrossRef]

59. Floyd, D.N.; Langham, S.; Séverac, H.C.; Levesque, B.G. The economic and quality-of-life burden of Crohn's disease in Europe and the United States, 2000 to 2013: A systematic review. Dig. Dis. Sci. 2015, 60, 299-312. [CrossRef]

60. Wilke, T.; Growth, A.; Long, G.H.; Tatro, A.R.; Sun, D. Rate of Adverse Events and Associated Health Care Costs for the Management of Inflammatory Bowel Disease in Germany. Clin. Ther. 2020, 42, 130-143.e3. [CrossRef]

61. Wright, E.K.; Kamm, M.A.; Cruz, P.D.; Hamilton, A.L.; Ritchie, K.J.; Bell, S.J.; Brown, S.J.; Connell, W.R.; Desmond, P.V.; Liew, D. Cost-effectiveness of Crohn's disease post-operative care. World J. Gastroenterol. 2016, 22, 3860-3868. [CrossRef] [PubMed]

62. Tan, J.J.; Tjandra, J.J. Laparoscopic surgery for Crohn's disease: A meta-analysis. Dis. Colon Rectum 2007, 50, 576-585. [CrossRef] [PubMed]

63. Feng, J.S.; Li, J.Y.; Yang, Z.; Chen, X.Y.; Mo, J.J.; Li, S.H. Stapled side-to-side anastomosis might be benefit in intestinal resection for Crohn's disease: A systematic review and network meta-analysis. Medicine 2018, 97, e0315. [CrossRef] [PubMed]

64. Kono, T.; Ashida, T.; Ebisawa, Y.; Chisato, N.; Okamoto, K.; Katsuno, H.; Maeda, K.; Fujiya, M.; Kohgo, Y.; Furukawa, H. A new antimesenteric functional end-to-end handsewn anastomosis: Surgical prevention of anastomotic recurrence in Crohn's disease. Dis. Colon Rectum 2011, 54, 586-592. [CrossRef]

65. Ng, C.H.; Chin, Y.H.; Lin, S.Y.; Koh, J.W.H.; Lieske, B.; Koh, F.H.; Chong, C.S.; Foo, F.J. Kono-S anastomosis for Crohn's disease: A systemic review, meta-analysis, and meta-regression. Surg. Today 2021, 51, 493-501. [CrossRef]

66. Luglio, G.; Rispo, A.; Imperatore, N.; Giglio, M.C.; Amendola, A.; Tropeano, F.P.; Peltrini, R.; Castiglione, F.; De Palma, G.D.; Bucci, L. Surgical Prevention of Anastomotic Recurrence by Excluding Mesentery in Crohn's Disease: The SuPREMe-CD Study-A Randomized Clinical Trial. Ann. Surg. 2020, 272, 210-217. [CrossRef]

67. Coffey, J.C.; O'Leary, D.P. The mesentery: Structure, function, and role in disease. Lancet Gastroenterol. Hepatol. 2016, 1, $238-247$. [CrossRef]

68. Li, Y.; Zhu, W.; Gong, J.; Shen, B. The role of the mesentery in Crohn's disease. Lancet Gastroenterol. Hepatol. 2017, 2, $244-245$. [CrossRef]

69. Li, Y.; Zhu, W.; Zuo, L.; Shen, B. The Role of the Mesentery in Crohn's Disease: The Contributions of Nerves, Vessels, Lymphatics, and Fat to the Pathogenesis and Disease Course. Inflamm. Bowel Dis. 2016, 22, 1483-1495. [CrossRef]

70. Karaskova, E.; Velganova-Veghova, M.; Geryk, M.; Foltenova, H.; Kucerova, V.; Karasek, D. Role of Adipose Tissue in Inflammatory Bowel Disease. Int. J. Mol. Sci. 2021, 22, 4226. [CrossRef]

71. Rivera, E.D.; Coffey, J.C.; Walsh, D.; Ehrenpreis, E.D. The Mesentery, Systemic Inflammation, and Crohn's Disease. Inflamm. Bowel Dis. 2018, 25, 226-234. [CrossRef] [PubMed]

72. Coffey, C.J.; Kiernan, M.G.; Sahebally, S.M.; Jarrar, A.; Burke, J.P.; Kiely, P.A.; Shen, B.; Waldron, D.; Peirce, C.; Moloney, M.; et al. Inclusion of the Mesentery in Ileocolic Resection for Crohn's Disease is Associated With Reduced Surgical Recurrence. J. Crohns Colitis 2018, 12, 1139-1150. [CrossRef] [PubMed]

73. Li, Y.; Mohan, H.; Lan, N.; Wu, X.; Zhou, W.; Gong, J.; Shen, B.; Stocchi, L.; Coffey, J.C.; Zhu, W. Mesenteric excision surgery or conservative limited resection in Crohn's disease: Study protocol for an international, multicenter, randomized controlled trial. Trials 2020, 21, 210. [CrossRef] [PubMed] 
74. Garofalo, E.; Lucarini, A.; Flashman, K.G.; Celentano, V. A positive proximal resection margin is associated with anastomotic complications following primary ileocaecal resection for Crohn's disease. Int. J. Colorectal Dis. 2019, 34, 1585-1590. [CrossRef]

75. Schineis, C.; Ullrich, A.; Lehmann, K.S.; Holmer, C.; Lauscher, J.C.; Weixler, B.; Kreis, M.E.; Seifarth, C. Microscopic inflammation in ileocecal specimen does not correspond to a higher anastomotic leakage rate after ileocecal resection in Crohn's disease. PLoS ONE 2021, 16, e0247796. [CrossRef]

76. Aaltonen, G.; Ristimäki, A.; Keränen, I.; Carpelan-Holmström, M.; Lepistö, A. Does a histologically inflamed resection margin increase postoperative complications in patients with Crohn's disease? Scand. J. Gastroenterol. 2018, 53, 279-283. [CrossRef]

77. Bemelman, W.A.; Warusavitarne, J.; Sampietro, G.M.; Serclova, Z.; Zmora, O.; Luglio, G.; de Buck van Overstraeten, A.; Burke, J.P.; Buskens, C.J.; Colombo, F.; et al. ECCO-ESCP Consensus on Surgery for Crohn's Disease. J. Crohns Colitis 2018, 12, 1-16. [CrossRef]

78. Tandon, P.; Malhi, G.; Abdali, D.; Pogue, E.; Marshall, J.K.; de Buck van Overstraeten, A.; Riddell, R.; Narula, N. Active Margins, Plexitis, and Granulomas Increase Postoperative Crohn's Recurrence: Systematic Review and Meta-analysis. Clin. Gastroenterol. Hepatol. 2021, 19, 451-462. [CrossRef]

79. Ryan, J.M.; Rogers, A.C.; O'Toole, A.; Burke, J.P. Meta-analysis of Histological Margin Positivity in the Prediction of Recurrence After Crohn's Resection. Dis. Colon Rectum 2019, 62, 882-892. [CrossRef]

80. Poredska, K.; Kunovsky, L.; Marek, F.; Kala, Z.; Prochazka, V.; Dolina, J.; Zboril, V.; Kovalcikova, P.; Pavlik, T.; Jabandziev, P.; et al. The Influence of Microscopic Inflammation at Resection Margins on Early Postoperative Endoscopic Recurrence After Ileocaecal Resection for Crohn's Disease. J. Crohns Colitis 2020, 14, 361-368. [CrossRef]

81. Riault, C.; Diouf, M.; Chatelain, D.; Yzet, C.; Turpin, J.; Brazier, F.; Dupas, J.L.; Sabbagh, C.; Nguyen-Khac, E.; Fumery, M. Positive histologic margins is a risk factor of recurrence after ileocaecal resection in Crohn's disease. Clin. Res. Hepatol. Gastroenterol. 2020, 2020, 101569. [CrossRef]

82. Hammoudi, N.; Cazals-Hatem, D.; Auzolle, C.; Gardair, C.; Ngollo, M.; Bottois, H.; Nancey, S.; Pariente, B.; Buisson, A.; Treton, X.; et al. Association Between Microscopic Lesions at Ileal Resection Margin and Recurrence After Surgery in Patients With Crohn's Disease. Clin. Gastroenterol. Hepatol. 2020, 18, 141-149.e2. [CrossRef] [PubMed]

83. Wasmann, K.; van Amesfoort, J.; van Montfoort, M.L.; Koens, L.; Bemelman, W.A.; Buskens, C.J. The Predictive Value of Inflammation at Ileocecal Resection Margins for Postoperative Crohn's Recurrence: A Cohort Study. Inflamm. Bowel Dis. 2020, 26, 1691-1699. [CrossRef] [PubMed]

84. Zemel, M.; Solo, E.; Tulchinsky, H. Does microscopic involvement of the surgical margins after ileocecectomy in Crohn's patients predict early recurrence? Int. J. Colorectal Dis. 2021. [CrossRef]

85. Ha, F.J.; Thong, L.; Khalil, H. Quality of Life after Intestinal Resection in Patients with Crohn Disease: A Systematic Review. Dig. Surg. 2017, 34, 355-363. [CrossRef] 